Document downloaded from:

http://hdl.handle.net/10251/126096

This paper must be cited as:

Montanes, N.; Garcia-Sanoguera, D.; Segui Llinares, VJ.; Fenollar, O.; Boronat, T. (2018). Processing and Characterization of Environmentally Friendly Composites from Biobased Polyethylene and Natural Fillers from Thyme Herbs. Journal of Polymers and the Environment. 26(3):1218-1230. https://doi.org/10.1007/s10924-017-1025-2

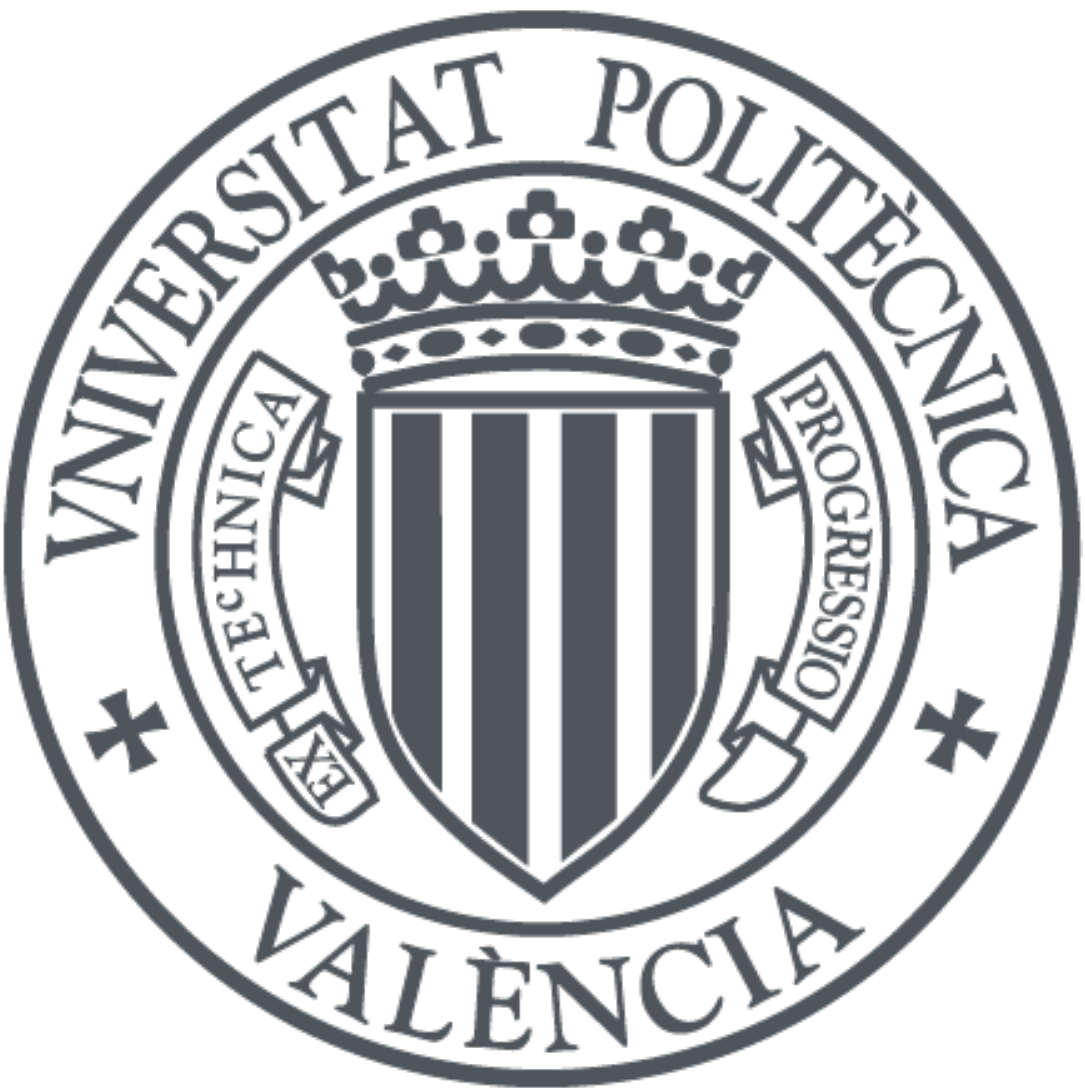

The final publication is available at

http://doi.org/10.1007/s10924-017-1025-2

Copyright Springer-Verlag

Additional Information 


\title{
"Processing and characterization of environmentally friendly composites from biobased polyethylene and natural fillers from thyme herbs"
}

N. Montanes, D. Garcia-Sanoguera, V.J. Segui, O. Fenollar, T. Boronat*

\author{
Materials Technology Institute \\ Universitat Politècnica de València \\ Plaza Ferrándiz y Carbonell, s/n - 03801 - Alcoy - Spain
}

* Correspondence to: T. Boronat

E-mail: tboronat@dimm.upv.es

Tel.: +34966528468 


\begin{abstract}
The main aim of this research work is to assess the potential of a distillery waste from thyme as multifunctional filler in natural fiber reinforced plastics (NFRP) with biobased polyethylene matrix. Several ethylene-based copolymers with different co-monomers (vinyl alcohol, methyl methacrylate, glycidyl methacrylate and acrylic acid) were used as compatibilizer agents to overcome the lack of compatibility between the highly hydrophobic matrix and the highly hydrophilic lignocellulosic filler. The effect of the compatibilizer type and amount, as well as the lignocellulosic filler content was followed by thermal, mechanical, morphological and rheological characterizations. In addition to the typical filler effect, thyme also provides a remarkable increase in thermal stability at moderate temperatures with a positive effect on widening the processing window. The compatibilizer agent that offers best balanced properties is the glycidyl methacrylate copolymer with a noticeable increase in stiffness, flexural and tensile strength. Regarding processability, the viscosity increases with the filler content. This is highly important at low shear rates but the effect is almost negligible at high shear rates typical of injection molding processes.
\end{abstract}

\title{
Keywords:
}

Natural fiber composites; particle reinforcement; mechanical properties; thermal properties; thyme 


\section{1.- Introduction.}

In the last years, increasing environmental concerns, petroleum depletion and the need of a sustainable development economical model are leading the research on environmentally friendly materials. This situation is especially pronounced in the plastics and composites industry. The challenge that these industries must assess in the following years is the development of high performance materials at competitive prices under an "eco-friendly" approach. In this approach, the use of materials from renewable resources is evolving as a solution to the issues related to petroleum depletion and the carbon footprint $[1,2]$. In fact, this approach has been the leading force to the development of some polymers from renewable resources as it is the case of bio-polyethylene which is alternately obtained through a biochemical route by Braskem starting from biobased feedstocks such as sugarcane $[3,4]$.

Wood plastic composites (WPCs) which consist on the combination of a commodity plastic matrix and a wood-type filler are gaining interest as environmentally friendly solutions. In fact, WPCs are a particular subgroup of the so called "natural fiber reinforced plastics" (NFRPs) which considers all type of polymer matrices and all types of lignocellulosic fillers coming from natural resources[2]. These new thermoplastic composites reinforced with lignocellulosic fillers find increasing uses in several sectors such as automotive [5-8], building $[9,10]$, packaging $[11$, 12], etc. Among the advantages that WPCs and NFRPs can provide, it is worth to mention their low cost, low density, high specific stiffness and strength, low maintenance, abundant availability of lignocellulosic fillers from industrial wastes, etc.[13] as well as their contribution to minimize the effects of petroleum depletion[14-16]. Natural fibers are cheaper and more abundant than inorganic fillers[17, 18]. Moreover, a wide variety of lignocellulosic fillers can be obtained as byproducts of the food industry and agroforestry thus contributing to minimize the problems related to their disposal. Today, natural fibers are widely used in bio-composites[19, 20]. They 
can be obtained from different plants such as banana [21], flax [8], hemp [22], pineapple [23], coconut [24], corn [15], rice [25], etc.

Thyme herbs consist of small evergreen herbaceous plants and shrubs belonging to the genus Thyme, which includes a wide variety of highly aromatic plants typical of temperate regions. Thymus moroderi (TM) is one of the 350 thyme varieties which is typical of the southeast of Spain. In general, thyme has been widely used as seasoning due to its aromatic and pharmacological properties[26]. Recent studies have reported synergistic antibacterial and antioxidant effects of thyme and its potential applications in the food industry and packaging sector[26, 27]. In a recent research, thyme was successfully used as natural food colorant as it contains anthocyanins (E-163)[28]. Additionally, it is highly rich in polyphenols which contributes to increased antioxidant activity. A wide variety of essential oils are industrially extracted from thyme[29]. Due to its excellent properties and particular flavors, thyme is also used in the beverage industry in both alcoholic[30] and non-alcoholic products[31]. This industrial activity generates important amounts of wastes that are currently dropped into controlled landfills or used for animal[32].

One of the main drawbacks of WPCs and NFRPs is the lack (or extremely low) of interactions between the hydrophobic polymer matrix and the highly hydrophilic nature of the lignocellulosic filler. These weak interface interactions are responsible for relatively poor mechanical properties, as stresses cannot be appropriately transferred. To overcome this phenomenon, different solutions have been successfully used. Coupling agents are employed to selectively modify the surface properties of the lignocellulosic filler by reducing its hydrophilicity, which has a positive effect on establishing interactions with the hydrophobic matrix $[17,18,25,33]$. In addition, compatibilizer agents also provide an interesting solution. Most compatibilizers consist on copolymers with dual functionality: non-polar segment chains and 
polar groups. This allows establishing interactions with both the polymer matrix (the hydrophobic segment chains) and the lignocellulosic particles (the hydrophilic/polar groups)[34, 35].

This work explores the possibility of using thyme wastes as lignocellulosic filler for the development of high environmentally friendly bio-composites with a biobased polyethylene matrix. The effectiveness of the compatibilizer type and amount on final performance of biocomposites is evaluated in terms of mechanical, thermal and rheological properties. In addition, the effect of the filler content on processability by injection molding is assessed by rheological characterization. 


\section{2.- Material and methods.}

\section{1.- Materials and sample preparation.}

A high-density polyethylene (HDPE) commercial grade SHA7260 supplied by Braskem (São Paulo, Brasil) was used as the base polymer for bio-composites. This HDPE grade is obtained from ethanol sugarcane, and has a positive effect on reducing the carbon footprint as it captures and fixes $\mathrm{CO}_{2}$ from the atmosphere. It possesses a density of $0.956 \mathrm{~g} \mathrm{~cm}^{-3}$ and a melt flow index of $20 \mathrm{~g} / 10 \mathrm{~min}\left(230^{\circ} \mathrm{C} / 2160 \mathrm{~g}\right)$.

The lignocellulosic filler was obtained from thyme wastes from a local liqueur company, Sinc distilleries (Alcoy, Spain). The particular thyme species used was Thymus moroderi, which is endemic to southeastern Spain, highly appreciated in the liqueur industry and folk medicine.

Different ethylene copolymers supplied by Sigma-Aldrich (Sigma-Aldrich Química, S.A., Madrid, Spain) were used as compatibilizer agents: poly(vinyl alcohol-co-ethylene) (PVAE), poly(ethylene-co-methyl acrylate-co-glycidyl methacrylate) (PEMAGM), poly(ethylene-coglycidyl methacrylate) (PEGM) and poly(ethylene-co-acrylic acid) (PEA).

First, thyme was dried for $48 \mathrm{~h}$ in an oven at $40^{\circ} \mathrm{C}$ in order to remove the residual alcohol from distillation; then it was milled and sieved with a $25 \mu \mathrm{m}$ mesh using an ultra-centrifugal mill ZM 200 by Retsch (Düsseldorf, Germany). HDPE, thyme powder and the corresponding compatibilizer type and amount were mechanically pre-mixed in a zipper bag, and then, compounded in a twin-screw co-rotating ZSK-18 MEGAlab laboratory extruder from Coperion (Stuttgart, Germany), screw diameter: $18 \mathrm{~mm}, \mathrm{~L} / \mathrm{D}$ ratio of 48 at a rotating speed of $40 \mathrm{rpm}$ with a temperature profile of $180^{\circ} \mathrm{C}$ (hopper), $180^{\circ} \mathrm{C}, 185^{\circ} \mathrm{C}, 190^{\circ} \mathrm{C}$ (die) and a nozzle diameter of 3 $\mathrm{mm}$. After this, composites were pelletized and subsequently molded in an injection molding machine Meteor 270/75 (Mateu \& Solé, Barcelona, Spain) at an injection temperature of $200{ }^{\circ} \mathrm{C}$ in 
a mirror finished steel mold with standard sample shapes for tensile, flexural and impact tests.

Table 1 lists all the samples prepared for this work.

\section{TABLE 1}

\section{2.- Thermal characterization of HDPE/thyme composites.}

The thermal properties of HDPE/thyme composites were investigated by differential scanning calorimetry (DSC) in a Mettler Toledo DSC 821e calorimeter (Mettler Toledo Inc., Schwerzenbach, Switzerland). Samples with an average size of 5 - $10 \mathrm{mg}$, were subjected to a heating program from $-50^{\circ} \mathrm{C}$ to $300^{\circ} \mathrm{C}$ at a heating rate of $20^{\circ} \mathrm{C} \mathrm{min}-1$. To evaluate the antioxidant effects of thyme, DSC tests were conducted under air atmosphere (40 $\left.\mathrm{mL} \mathrm{min}^{-1}\right)$. Degradation at high temperatures was followed by thermogravimetric analysis (TGA) in a Mettler-Toledo 851eTGA-SDTA thermobalance (Mettler Toledo Inc., Schwerzenbach, Switzerland). TGA tests were carried out with standard alumina crucibles $(70 \mu \mathrm{L})$ in nitrogen atmosphere $\left(20 \mathrm{~mL} \mathrm{~min}^{-1}\right)$ to prevent thermo-oxidative reactions. Samples of 5 - $10 \mathrm{mg}$ were subjected to a heating program from $30^{\circ} \mathrm{C}$ up to $900{ }^{\circ} \mathrm{C}$ at a heating rate of $20^{\circ} \mathrm{C} \mathrm{min}-1$.

\section{3.- Mechanical characterization of HDPE/thyme composites.}

Tensile and flexural tests were carried out according to ISO 527-1:2012[36] and ISO 178:2011[37], respectively. Both tests were conducted in a universal flexural test machine ELIB 30 (S.A.E. Ibertest, Madrid, Spain) equipped with a $5 \mathrm{kN}$ load cell. The crosshead rate was set to 5 $\mathrm{mm} \mathrm{min}-1$ and $10 \mathrm{~mm} \mathrm{~min}^{-1}$ for tensile and flexural tests respectively. Hardness measurements were run according to ISO 868:2003[38], using a durometer model 676-D (J. Bot Instruments, Barcelona, Spain). The impact strength was measured using a $1 \mathrm{~J}$ Charpy's pendulum from 
Metrotec (San Sebastian, Spain) according to ISO 179-1:2010[39]. All mechanical tests were carried out on five different samples at room temperature; the presented values correspond to their average.

\section{4.- Morphology of HDPE/thyme composites.}

Fractured samples from impact tests of HDPE/thyme composites were observed using a field emission scanning electron microscope (FESEM) Zeiss Ultra 55 (Zeiss Oxford Instruments, Abingdon, United Kingdom). All specimens were previously coated with a thin aurumpalladium layer in a sputter coater Emitech mod. SC7620 (Quorum Technologies Ltd., East Sussex, UK).

\section{5.- Rheology of HDPE/thyme composites.}

The rheology study of HDPE/thyme composites was carried out using a capillary rheometer model Rheoflixer MT (Thermo Haake, Germany) at $190^{\circ} \mathrm{C}$ and $210^{\circ} \mathrm{C}$. After charging the material into the rheometer barrel, it remained for five minutes to ensure complete melting. All the measurements were done with a $1 \mathrm{~mm}$ diameter (D) die and an L/D ratio of 10 . The viscosity measurements were made over a range of shear rates from 100 to $10000 \mathrm{~s}^{-1}$ according to ISO 11443:2014[40], typically covered by injection molding processes. The results correspond with the average of five experimental tests for each sample. The rheological analysis was done with the aim to determine the general trends for a comparison. For this reason, no end-corrections were made, which allow to calculate the real viscosity values. 


\section{3.- Results and discussion.}

\section{1.- The effect of different coupling agents on performance of HDPE/thyme composites.}

The hydrophilic nature of lignocellulosic particles is the main drawback in order to use them as a filler in polymeric composites. HDPE is a non-polar polymer with a pronounced hydrophobic behavior. This high difference in polarity between the polymer matrix and the filler leads to poor polymer-particle interactions, which in turn, are responsible for poor mechanical performance. Compatibilizer agents, typically copolymers, are characterized by a dual functionality that allows interactions with both the hydrophobic polymer matrix and the hydrophilic filler, with a positive effect on overall properties. Table 2 summarizes the main thermal parameters of HDPE/thyme composites with different ethylene-based copolymer compatibilizers as obtained by differential scanning calorimetry (DSC) at moderate temperatures with typical thermo-oxidative processes. The compatibilizer content has been set to a constant percentage of $3 \mathrm{wt} \%$ (which stands for a $10 \%$ of the filler content).

\section{TABLE 2}

Unfilled HDPE possesses a melt enthalpy of $178.2 \mathrm{~J} \mathrm{~g}^{-1}$ and, obviously, thyme filler provides a dilution effect, which leads to lower the melt enthalpy values. The most relevant effect of the thyme filler is a remarkable increase in the degradation onset. Thermo-oxidative processes start at $237.0{ }^{\circ} \mathrm{C}$ on unfilled HDPE. Uncompatibilized composites containing $30 \mathrm{wt} \%$ thyme enhances the thermal stability up to degradation onset values of $270.8^{\circ} \mathrm{C}$. The compatibilizer type does not play a key role in the thermal stabilization of HDPE to thermo-oxidative processes and the addition of all four ethylene-based copolymers as compatibilizer agents does not change the degradation onset in a great extent. With regard to degradation at high temperatures 
(decomposition range), Fig. 1 gathers the thermograms obtained by thermogravimetry, TGA whilst the corresponding degradation temperatures obtained by TGA are collected in Table 2.

\section{FIGURE 1}

Neat HDPE presents a one-step weight loss, which is ranged between $390^{\circ} \mathrm{C}$ and $508^{\circ} \mathrm{C}$. The TGA curve of thyme powder presents a three-step degradation profile. In the first stage, located between $75{ }^{\circ} \mathrm{C}$ and $108{ }^{\circ} \mathrm{C}$, an initial weight loss of $3.5 \mathrm{wt} \%$ is observed and can be attributed to the removal of residual water. In the second stage, comprised between $200{ }^{\circ} \mathrm{C}$ and $400{ }^{\circ} \mathrm{C}$, an important weight loss of $67 \mathrm{wt} \%$ is attributed to the degradation of cellulose, hemicellulose and lignin. Hemicellulose and cellulose degrades in a relatively narrow temperature range comprised between $220^{\circ} \mathrm{C}$ and $290^{\circ} \mathrm{C}$. With regard to lignin, it degrades in a wider range from $200{ }^{\circ} \mathrm{C}$ up to $750{ }^{\circ} \mathrm{C}$. Degradation of lignin overlaps the second and third stages. In the third stage, there is a negligible weight loss and the material is charred [33, 41-43]. The thermal degradation of lignin and pure cellulose was studied by Hornsby [44]; cellulose produces a char residue of $9.8 \mathrm{wt} \%$ and lignin produces a bigger char residue of $33.8 \mathrm{wt} \%$ at $750{ }^{\circ} \mathrm{C}$. HDPE/thyme composites degrade in a three-stage weight loss process. Nevertheless, the initial stage, which corresponds to water removal, is almost negligible with an associated weight loss of less than $1 \mathrm{wt} \%$. The second stage starts at $200^{\circ} \mathrm{C}$ and is attributed to filler degradation. The third stage, with a clear weight loss at higher temperatures corresponds to HDPE thermal degradation.

HDPE decomposition starts at about $364.5^{\circ} \mathrm{C}$ whilst thyme starts degradation at about $118{ }^{\circ} \mathrm{C}$. The uncompatibilized HDPE composite with $30 \mathrm{wt} \%$ thyme shows decreased thermal stability at high temperatures due to the presence of the lignocellulosic filler. Nevertheless, the overall thermal stability of the composite is much higher than that of the neat thyme flour. In fact, 
the onset decomposition temperature moves to $278^{\circ} \mathrm{C}$ without any compatibilizer. Moreover, the use of three compatibilizer agents (PEA, PEGM and PEMAGM) leads to a remarkable improvement of the thermal stability with onset decomposition temperatures around $290^{\circ} \mathrm{C}$. This could be representative for somewhat polymer-particle interactions due to the dual functionality that compatibilizers can provide. This interaction could also have a positive effect on mechanical performance of HDPE/thyme composites. Table 3 summarizes the effect of the four different ethylene-based copolymers on mechanical properties of compatibilized HDPE/thyme composites.

\section{TABLE 3}

Unfilled HDPE offers a tensile strength of 19.6 MPa and very high elongation at break of $520 \%$. As the tensile modulus represents the ratio of the applied stress to the obtained elongation in the linear or quasi-linear region, neat HDPE shows a tensile modulus of $373 \mathrm{MPa}$. The addition of $30 \mathrm{wt} \%$ thyme flour gives a remarkable decrease in elongation at break down to values of $2.83 \%$ and a slight decrease on tensile strength with typical values of $16.2 \mathrm{MPa}$. These results are due to the lack of compatibility between the highly hydrophobic HDPE matrix and the highly hydrophilic lignocellulosic filler. In fact, the randomly dispersed filler acts as a stress concentrator[45] and this has a negative effect on the material's cohesion[25]. For this reason, both mechanical resistant (tensile strength) and ductile (elongation at break) properties are lower. But it is important to remark that the decrease in elongation at break is much pronounced than that observed for tensile strength. On the other hand, the tensile modulus which stands for the overall stiffness, increases. These phenomena lead to an increase in tensile modulus up to values of 645 $\mathrm{MPa}$. This is the typical behavior of an uncompatibilized polymer-filler composite material. 
Compatibilizer agents act as a bridge between the polymer and the filler. Their dual functionality is able to react/interact with both the polymer matrix and the dispersed filler particles. All four ethylene-based compatibilizers give improved mechanical properties. In fact, all tensile strength values of the compatibilized systems are higher than that of the uncompatibilized system $(>17$ $\mathrm{MPa}$ ). It is worth to note the tensile strength of the HDPE/thyme composite compatibilized with PEGM with a value of 23.6 MPa which is the highest tensile strength of all four compatibilized composites. In addition, the elongation at break is also improved up to values of $3.63 \%$ which is a clear evidence of the compatibilizing effect. As a consequence, the tensile modulus decreases, thus indicating less rigid materials. Similar findings can be observed for flexural properties. Flexural work is not as aggressive as tensile work in these particle-filled materials. For this reason, both the flexural modulus and strength increases with addition of thyme filler. It is again the PEGM compatibilized HDPE/thyme composite the one with the highest flexural strength (33.2 $\mathrm{MPa}$ ) which is remarkably higher than unfilled HDPE (23.9 $\mathrm{MPa})$ and uncompatibilized HDPE/thyme composite (27.2 MPa). Regarding hardness, the use of different compatibilizers does not promote significant changes although slightly higher values are obtained in compatibilized systems[46]. Finally, with regard to the impact-absorbed energy (Charpy's impact energy), neat HDPE offers the highest energy value $\left(3.1 \mathrm{~kJ} \mathrm{~m}^{-2}\right)$. All composites (uncompatibilized and compatibilized) show a slightly lower energy absorption. Nevertheless, once again, the PEGM compatibilized composite shows good balance with an energy absorption of $2.6 \mathrm{~kJ} \mathrm{~m}^{-2}$ which is the maximum of the uncompatibilized and compatibilized systems[25]. The compatibilizing effect of the different ethylene-based copolymers can be observed in Fig. 2 that shows FESEM images of fractured surfaces from impact tests. As one can see, a small gap between the filler particle can be observed. This is due to the lack (or extremely low) of interactions between the dispersed filler particles and the surrounding polymer matrix. With regard to the 
PEGM compatibilized HDPE/thyme composite (Fig. 2c) it is evident that the gap has been noticeably reduced and it seems that particle filler is appropriately wetted by the surrounding polymer matrix. This allows stress transfer between the polymer and the dispersed filler particles with a clear improvement of mechanical performance as described previously. By taking into account overall mechanical and thermal properties, the HDPE/thyme composite with optimum/balanced properties is the one compatibilized with PEGM.

\section{FIGURE 2}

\section{2.- The effect of the PEGM coupling agent content on performance of HDPE/thyme composites.}

In the previous section, PEGM has been found as the optimum compatibilizer agent for the HDPE/thyme system. This section shows the effect of the compatibilizer content $(1.5,3.0,4.5$ and $6.0 \mathrm{wt} \%)$ on the overall thermal and mechanical and thermal properties of HDPE/thyme composites containing a constant filler content of $30 \mathrm{wt} \%$. Table 4 gathers the most relevant information obtained by thermal analysis. As it can be seen, the melt peak temperature does not change in a great extent with values in the $137-140{ }^{\circ} \mathrm{C}$ range. Regarding the onset degradation temperature (thermo-oxidative degradation), uncompatibilized HDPE/thyme composites show a temperature peak of $270.8^{\circ} \mathrm{C}$ which remains almost constant for a wt $\%$ compatibilizer of 5 and $10 \mathrm{wt} \%$ with regard to the total filler content. As the compatibilizer agent increases, a decreasing tendency in the onset degradation temperature can be observed down to values of $264.9^{\circ} \mathrm{C}$.

\section{TABLE 4}


Fig. 3 shows a comparative plot of the TGA thermograms of HDPE/thyme composites according to PEGM content ranging from 0 to $6.0 \mathrm{wt} \%$. As discussed previously, the thermal degradation of the HDPE/thyme composites proceeds in a three-stage process, although the stage corresponding to water removal cannot be observed due to the high content on HDPE (Table 4). For this reason, the degradation process can be divided into two clear stages: the first one attributed to lignocellulosic degradation and the second one, attributable to HDPE decomposition. As one can see, PEGM compatibilizer has a positive effect on the overall thermal stability regarding the uncompatibilized HDPE/thyme composite. The onset temperature of the

first and second steps is located at $195{ }^{\circ} \mathrm{C}$ and $399{ }^{\circ} \mathrm{C}$ respectively for the uncompatibilized HDPE/thyme composite. Both characteristic temperatures are moved to higher values of about $230{ }^{\circ} \mathrm{C}$ (first step) and $425^{\circ} \mathrm{C}$ (second step) in compatibilized HDPE/thyme composites with no clear tendency. Similar findings can be observed for a characteristic temperature corresponding to a weight loss of $2 \mathrm{wt} \%$.

\section{FIGURE 3}

\section{TABLE 5}

The effect of the compatibilizer amount on mechanical (tensile and flexural) properties of HDPE/thyme composites can be observed in Table 5. In uncompatibilized HDPE/thyme composites, the thyme flour behaves merely as a filler with no reinforcing effects because of the lack of polymer-particle interactions as stated before. The total compatibilizer content does not affect in a remarkable way to final properties. There is a clear improvement with regard to uncompatibilized composites but the amount of compatibilizer does not change in a great extent 
the different mechanical properties. Nevertheless, some slight changes can be detected. The HDPE/thyme composite compatibilized with 1.5 wt\% PEGM shows the lowest energy absorption obtained for all compositions. In general, addition of PEGM in the $1.5-6.0 \mathrm{wt} \%$ provides increased elongation at break with values of $4 \%$. Maximum values of both tensile and flexural strength are obtained for a PEGM content of $3.0 \mathrm{wt} \%$.

As observed, the results confirm that PEGM improves both the mechanical and thermal properties. In order to obtain this improvement, it is not necessary to add high amounts of compatibilizer since with low percentages give balanced mechanical and thermal properties.

\section{3.- Effect of the wt\% thyme flour on HDPE/thyme composites.}

This section shows the effect of the filler content on mechanical and thermal properties of HDPE/ thyme composites. The selected compatibilizer is poly(ethylene-co-glycidyl methacrylatePEGM and the its content was set to $10 \mathrm{wt} \%$ with regard to the total filler content. Fig. 4 shows a comparative plot of DSC thermograms of HDPE/thyme composites with varying thyme content.

\section{FIGURE 4}

An endothermic peak centered at $136{ }^{\circ} \mathrm{C}$ reveals the melting temperature of unfilled HDPE. This temperature is not significantly altered by the addition of thyme flour with typical melting temperatures around $138^{\circ} \mathrm{C}$. Regarding the degradation temperature, caused by the thermos-oxidative processes, an increasing trend is observed when thyme load increases. This is due to the presence of phenolic compounds in the thymus, which act as antioxidants, such as flavone and flavanone[26, 47]. Neat HDPE shows an onset degradation temperature of $253.6^{\circ} \mathrm{C}$ and this is highly increased up to values of $286^{\circ} \mathrm{C}$ with a filler content of $50 \mathrm{wt} \%$, thus showing a 
remarkable improvement of the thermal stability at moderate temperatures. With regard to degradation/decomposition at high temperatures, the lignocellulosic filler degrades at lower temperatures than those of the neat HDPE. Fig. 5 shows the TGA curves of the HDPE/thyme composites with different thyme content up to $50 \mathrm{wt} \%$. The first weight loss corresponds to the degradation of cellulose and hemicellulose whilst the second weight loss is representative for the HDPE decomposition. Obviously, as the filler content increases the first degradation step increases. These results agree with the findings of Avérous \& Le Digabel [20] in PBAT matrix composites with natural fillers. Similarly, the degradation range for the lignocellulosic filler obtained by other authors [48] (around $260^{\circ} \mathrm{C}$ ) is consistent with the reported results. It is worth to note that HDPE/thyme composites show full thermal stability up to $200{ }^{\circ} \mathrm{C}$ which makes this filler suitable for plastic processing processes.

\section{FIGURE 5}

The mechanical properties of HDPE/thyme composites are critical from a practical standpoint. The mechanical properties obtained by flexural and tensile tests of HDPE/thyme composites with varying thyme content are reported in Table 6.

\section{TABLE 6}

As it has been stated previously, uncompatibilized HDPE/thyme composites show a decrease in both mechanical resistant (tensile strength) and ductile (elongation at break) properties. The compatibilizer enhances polymer-filler interactions and this has a positive effect on stress transfer, which in turn, leads to an increase in both tensile strength and elongation at 
break with a clear reinforcing effect. The tensile strength of neat HDPE is 19.6 MPa and increases up to $26 \mathrm{MPa}$ in HDPE/ thyme composites with $50 \mathrm{wt} \%$ thyme. Similar tendency can be found for the flexural strength that changes from 23.9 MPa (neat HDPE) up to 37.1 MPa (HDPE/thyme composite with $50 \mathrm{wt} \%$ thyme). Regarding stiffness, both tensile and flexural modulus increase with the filler content. All these results are a clear evidence of the reinforcing effect that thyme filler provides to HDPE-based composites. Fig. 6 shows the variation of the Shore D hardness and the Charpy's impact energy of HDPE/thyme composites with varying thyme content. As the filler content increases, the material becomes harder which has a positive effect on the overall performance in wear and friction conditions. On the other hand, thyme filler gives more brittle materials but the compatibilizer causes that the absorbed energy for filled composites remains constant with a slight upward trend.

\section{FIGURE 6}

As indicated previously the microstructure of the fractured surface from impact test was analyzed by FESEM. A uniform dispersion of the thyme flour particles in the HDPE matrix is observed for all the concentrations (Fig. 7). It is important to note the absence of gaps between the thyme particles and the surrounding HDPE matrix thus indicating improved polymerparticle interactions due to the presence of the compatibilizer agent.

\section{FIGURE 7}

A rheological analysis was done in order to analyze the processability of the composites. Fig. 8 shows the dependence of the viscosity of HDPE/thyme composites with different thyme 
content in terms of the shear rate. The role of thyme flour in shear flow behavior of the melt composites can indeed be perceived through the different thyme content. In Fig. 8 it can be seen that viscosity increases with increasing filler content; this phenomenon is due to the high specific area of the filler, which prevents the polymer melt to flow. All HDPE/thyme composites show a pseudoplastic behavior. At low shear rates HDPE/thyme composites with high thyme content would present some processing difficulties due to high viscosity values. This issue can appear in manufacturing processes such thermoforming. As viscosity decreases with increasing shear rate, this topic is not important in techniques that typically use high shear rates such as extrusion and injection molding. The effect of temperature on shear rate viscosity is also shown in Fig. 8. Temperature is a key parameter in rheological measurements since it influences directly viscosity results. The presence of fillers in composite materials causes a viscosity increase, which could potentially impair processability. A temperature increase could counteract the increase in viscosity and therefore, the overall processability is not affected, but it is important to take into account that over $250{ }^{\circ} \mathrm{C}$ thermo-oxidative processes begin. The decrease in viscosity produced by the temperature increase is a result of the thermal motion of the molecules which causes a greater free volume in the polymer and, consequently, there is less intermolecular and intramolecular resistance[49].

\section{FIGURE 8}

\section{4.- Conclusions.}

The potential use of thyme wastes (Thymus modoreri) as multifunctional filler in wood plastic composites with a biobased HDPE matrix was studied. Thyme flour (up to $50 \mathrm{wt} \%$ ) was 
successfully incorporated into HDPE matrix by extrusion and subsequently processed by injection molding. The thyme waste contributes to a remarkable increase in the stability to thermo-oxidative processes. The role of thyme flour in uncompatibilized HDPE/thyme composites is the typical of an inert filler but the addition of a small amount of a compatibilizer agent leads to improved mechanical and thermal properties. Among different ethylene-based compatibilizers poly(ethylene-co-glycidyl methacrylate-PEGM gave the best balanced mechanical and thermal properties. In conclusion, HDPE/thyme composites represent a high environmentally friendly alternative to upgrade industrial wastes such as those derived from thyme. Thyme filler improves the overall resistance to thermo-oxidation and, in addition, it exerts a reinforcing effect by increasing polymer-particle interactions with a compatibilizer agent.

\section{Acknowledgments.}

This research was supported by the Ministry of Economy and Competitiveness MINECO through the grant number MAT2014-59242-C2-1-R. Authors also wish to thank “Licores Sinc, S.A." for kindly supplying the Thymus moroderi wastes. 


\section{References}

1. Kord, B., P. Ravanfar, and N. Ayrilmis, Influence of Organically Modified Nanoclay on Thermal and Combustion Properties of Bagasse Reinforced HDPE Nanocomposites. Journal of Polymers and the Environment: p. 1-10.

2. Satyanarayana, K.G., G.G.C. Arizaga, and F. Wypych, Biodegradable composites based on lignocellulosic fibers-An overview. Progress in Polymer Science, 2009. 34(9): p. 982-1021.

3. Boronat, T., et al., Development of a biocomposite based on green polyethylene biopolymer and eggshell. Materials \& Design, 2015. 68: p. 177-185.

4. Carbonell-Verdú, A., et al., Development of slate fiber reinforced high density polyethylene composites for injection molding. Composites Part B: Engineering, 2015. 69: p. 460-466.

5. Alves, C., et al., Ecodesign of automotive components making use of natural jute fiber composites. Journal of Cleaner Production, 2010. 18(4): p. 313-327.

6. $\quad$ Ashori, A., Wood-plastic composites as promising green-composites for automotive industries! Bioresource Technology, 2008. 99(11): p. 4661-4667.

7. Shalwan, A. and B.F. Yousif, In State of Art: Mechanical and tribological behaviour of polymeric composites based on natural fibres. Materials \& Design, 2013. 48: p. 14-24.

8. Farag, M.M., Quantitative methods of materials substitution: Application to automotive components. Materials \& Design, 2008. 29(2): p. 374-380.

9. John, M.J. and S. Thomas, Biofibres and biocomposites. Carbohydrate Polymers, 2008. 71(3): p. 343-364.

10. Christian, S. and S. Billington, Sustainable Biocomposites for Construction. Composites and polycon, 2009: p. 15-17.

11. Berthet, M.-A., et al., Torrefaction treatment of lignocellulosic fibres for improving fibre/matrix adhesion in a biocomposite. Materials \& Design, 2016. 92: p. 223-232.

12. Yang, H.-S., et al., Water absorption behavior and mechanical properties of lignocellulosic fillerpolyolefin bio-composites. Composite Structures, 2006. 72(4): p. 429-437.

13. Syed, M.A., et al., Studies on the Physico-Mechanical, Thermal, and Morphological Behaviors of High Density Polyethylene/Coleus Spent Green Composites. Journal of Applied Polymer Science, 2011. 119(4): p. $1889-1895$.

14. Ferrero, B., et al., Green Composites Based on Wheat Gluten Matrix and Posidonia Oceanica Waste Fibers as Reinforcements. Polymer Composites, 2013. 34(10): p. 1663-1669.

15. Matkó, S., et al., Flame retardancy of biodegradable polymers and biocomposites. Polymer Degradation and Stability, 2005. 88(1): p. 138-145.

16. Thakur, M.K., et al., Synthesis and Applications of Biodegradable Soy Based Graft Copolymers: A Review. Acs Sustainable Chemistry \& Engineering, 2016. 4(1): p. 1-17.

17. Colom, X., et al., Effects of different treatments on the interface of HDPE/lignocellulosic fiber composites. Composites Science and Technology, 2003. 63(2): p. 161-169.

18. Habibi, Y., et al., Processing and characterization of reinforced polyethylene composites made with lignocellulosic fibers from Egyptian agro-industrial residues. Composites Science and Technology, 2008. 68(7-8): p. 1877-1885.

19. Faruk, O., et al., Biocomposites reinforced with natural fibers: 2000-2010. Progress in Polymer Science, 2012. 37(11): p. 1552-1596.

20. Avérous, L. and F. Le Digabel, Properties of biocomposites based on lignocellulosic fillers. Carbohydrate Polymers, 2006. 66(4): p. 480-493.

21. Satapathy, S. and R.V.S. Kothapalli, Mechanical, Dynamic Mechanical and Thermal Properties of Banana Fiber/Recycled High Density Polyethylene Biocomposites Filled with Flyash Cenospheres. Journal of Polymers and the Environment, 2017: p. 1-14.

22. Elkhaoulani, A., et al., Mechanical and thermal properties of polymer composite based on natural fibers: Moroccan hemp fibers/polypropylene. Materials \& Design, 2013. 49: p. 203-208.

23. Arib, R.M.N., et al., Mechanical properties of pineapple leaf fibre reinforced polypropylene composites. Materials \& Design, 2006. 27(5): p. 391-396.

24. Olumuyiwa, A.J., T.S. Isaac, and S.O. Samuel, Study of mechanical behaviour of coconut shell reinforced polymer matrix composite. Journal of Minerals and Materials Characterization and Engineering, 2012. 11(08): p. 774.

25. Yang, H.-S., et al., Effect of different compatibilizing agents on the mechanical properties of lignocellulosic material filled polyethylene bio-composites. Composite Structures, 2007. 79(3): p. 369-375. 
26. Ruiz-Navajas, Y., et al., Chemical characterization and antibacterial activity of Thymus moroderi and Thymus piperella essential oils, two Thymus endemic species from southeast of Spain. Food Control, 2012. 27(2): p. 294-299.

27. Ruiz-Navajas, Y., et al., In vitro antibacterial and antioxidant properties of chitosan edible films incorporated with Thymus moroderi or Thymus piperella essential oils. Food Control, 2013. 30(2): p. 386392.

28. Díaz-García, M.C., et al., Production of an anthocyanin-rich food colourant from Thymus moroderi and its application in foods. Journal of the Science of Food and Agriculture, 2015. 95(6): p. 1283-1293.

29. Perdones, Á., A. Chiralt, and M. Vargas, Properties of film-forming dispersions and films based on chitosan containing basil or thyme essential oil. Food Hydrocolloids, 2016. 57: p. 271-279.

30. Meybodi, N.M., M.T. Ebrahimi, and A.M. Mortazavian, Ethnic Fermented Foods and Beverage of Iran, in Ethnic Fermented Foods and Alcoholic Beverages of Asia. 2016, Springer. p. 309-322.

31. Arsenijević, J., et al., Bioactivity of herbal tea of Hungarian thyme based on the composition of volatiles and polyphenolics. Industrial Crops and Products, 2016. 89: p. 14-20.

32. Boutoial, K., et al., Effect of feeding goats with distilled and non-distilled thyme leaves (Thymus zygis subp. gracilis) on milk and cheese properties. Journal of dairy research, 2013. 80(04): p. 448-456.

33. Tserki, V., et al., Novel biodegradable composites based on treated lignocellulosic waste flour as filler. Part I. Surface chemical modification and characterization of waste flour. Composites Part A: Applied Science and Manufacturing, 2005. 36(7): p. 965-974.

34. Sailaja, R., Mechanical properties of esterified tapioca starch-LDPE blends using LDPE-co-glycidyl methacrylate as compatibilizer. Polymer international, 2005. 54(2): p. 286-296.

35. Revert, A., et al., Upgrading brewer's spent grain as functional filler in polypropylene matrix. Polymer Composites, 2015.

36. ISO, Plastics - Determination of tensile properties - Part 1: General principles. 2012.

37. ISO, Plastics. determination of flexural properties. 2011.

38. ISO, Plastics and ebonite. Determination fo indentation hardness by means of durometer (Shore Hardness). 2003.

39. ISO, Plastics. Determination of charpy impact properties - Part 1: Non-instrumented impact test. 2010.

40. ISO, Plastics - Determination of the fluidity of plastics using capillary and slit-die rheometers. 2014.

41. Perinovic, S., B. Andricic, and M. Erceg, Thermal properties of poly(L-lactide)/olive stone flour composites. Thermochimica Acta, 2010. 510(1-2): p. 97-102.

42. Salasinska, K. and J. Ryszkowska, Natural fibre composites from polyethylene waste and hazelnut shell: dimensional stability, physical, mechanical and thermal properties. Composite Interfaces, 2012. 19(5): p. 321-332.

43. Yussuf, A.A., I. Massoumi, and A. Hassan, Comparison of Polylactic Acid/Kenaf and Polylactic Acid/Rise Husk Composites: The Influence of the Natural Fibers on the Mechanical, Thermal and Biodegradability Properties. Journal of Polymers and the Environment, 2010. 18(3): p. 422-429.

44. Hornsby, P.R., E. Hinrichsen, and K. Tarverdi, Preparation and properties of polypropylene composites reinforced with wheat and flax straw fibres: Part I Fibre characterization. Journal of Materials Science, 1997. 32(2): p. 443-449.

45. Adhikary, K.B., S.S. Pang, and M.P. Staiger, Dimensional stability and mechanical behaviour of woodplastic composites based on recycled and virgin high-density polyethylene (HDPE). Composites Part BEngineering, 2008. 39(5): p. 807-815.

46. Rahman, M.R., et al., Mechanical properties of polypropylene composites reinforced with chemically treated abaca. Composites Part a-Applied Science and Manufacturing, 2009. 40(4): p. 511-517.

47. Ruiz-Navajas, Y., et al., In Vitro Antioxidant and Antifungal Properties of Essential Oils Obtained from Aromatic Herbs Endemic to the Southeast of Spain. Journal of Food Protection, 2013. 76(7): p. 1218-1225.

48. Ruseckaite, R.A. and A. Jiménez, Thermal degradation of mixtures of polycaprolactone with cellulose derivatives. Polymer Degradation and Stability, 2003. 81(2): p. 353-358.

49. Williams, M.L., R.F. Landel, and J.D. Ferry, Mechanical Properties of Substances of High Molecular Weight. 19. The Temperature Dependence of Relaxation Mechanisms in Amorphous Polymers and Other Glass-forming Liquids. Journal of the American Chemical Society, 1955. 77(14): p. 3701-3707. 


\section{Figure captions}

Figure 1.- Plot comparison of the thermogravimetric (TGA) curves of HDPE/thyme composites with $30 \mathrm{wt} \%$ thyme filler and $3 \mathrm{wt} \%$ of different compatibilizer agents.

Figure 2.- FESEM images of fractured surfaces from impact test of HDPE/thyme composites at $500 \times$ with $30 \mathrm{wt} \%$ thyme filler and a constant content ( $3 \mathrm{wt} \%)$ of different compatibilizer agents

(a) uncompatibilized, (b) poly(ethylene-co-acrylic acid)-PEA, (c) poly(ethylene-co-glycidyl methacrylate)-PEGM, (d) poly(vinyl alcohol-co-ethylene)-PVAE and (e) poly(ethylene-co-methyl acrylate-co-glycidyl methacrylate)-PEMAGM.

Figure 3.- Plot comparison of the thermogravimetric (TGA) curves of HDPE/ thyme composites with $30 \mathrm{wt} \%$ thyme filler and varying compatibilizer content, poly(ethylene-co-glycidyl methacrylate).

Figure 4.- Plot comparison of the differential scanning calorimetry (DSC) thermograms for HDPE/ thyme composites with varying thyme filler content and a compatibilizer content (10\% of the total filler content) of poly(ethylene-co-glycidyl methacrylate-PEGM.

Figure 5.- Plot comparison of the thermogravimetric (TGA) curves for HDPE/thyme composites with varying thyme filler content and a compatibilizer content $(10 \%$ of the total filler content) of poly(ethylene-co-glycidyl methacrylate-PEGM.

Figure 6.- Plot evolution of the Shore D hardness and Charpy's impact energy of HDPE/thyme composites with varying thyme filler content and a compatibilizer content $(10 \%$ of the total filler content) of poly(ethylene-co-glycidyl methacrylate-PEGM.

Figure 7.- FESEM images of fractured surfaces from impact test of HDPE/thyme composites at $500 \times$ with varying thyme filler content and a compatibilizer content $(10 \%$ of the total filler content) of poly(ethylene-co-glycidyl methacrylate-PEGM: a) $10 w t \%, b) 20 w t \%, c) 30 w t \%$, d) 40 wt $\%$ and e) $50 w t \%$. 
Figure 8.- Capillary rheology of HDPE/thyme composites, a) variation of apparent shear viscosity as a function of the thyme filler content, b) variation of apparent shear viscosity in terms of temperature. 


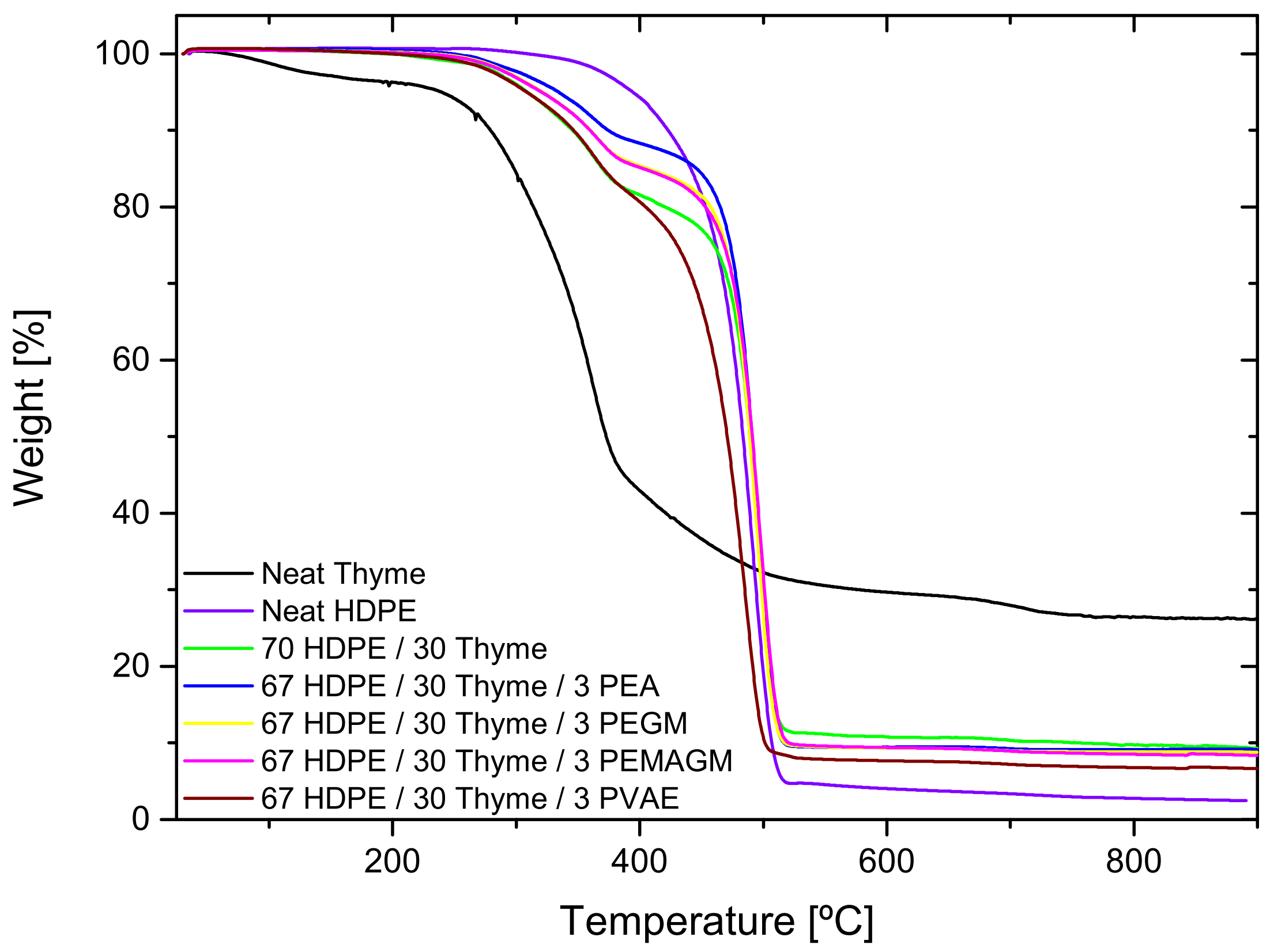


Figure 2.- FESEM images of fractured surfaces from impact test of

HDPE/thyme composites at $500 \times$ with 30 wt $\%$ thyme filler and a
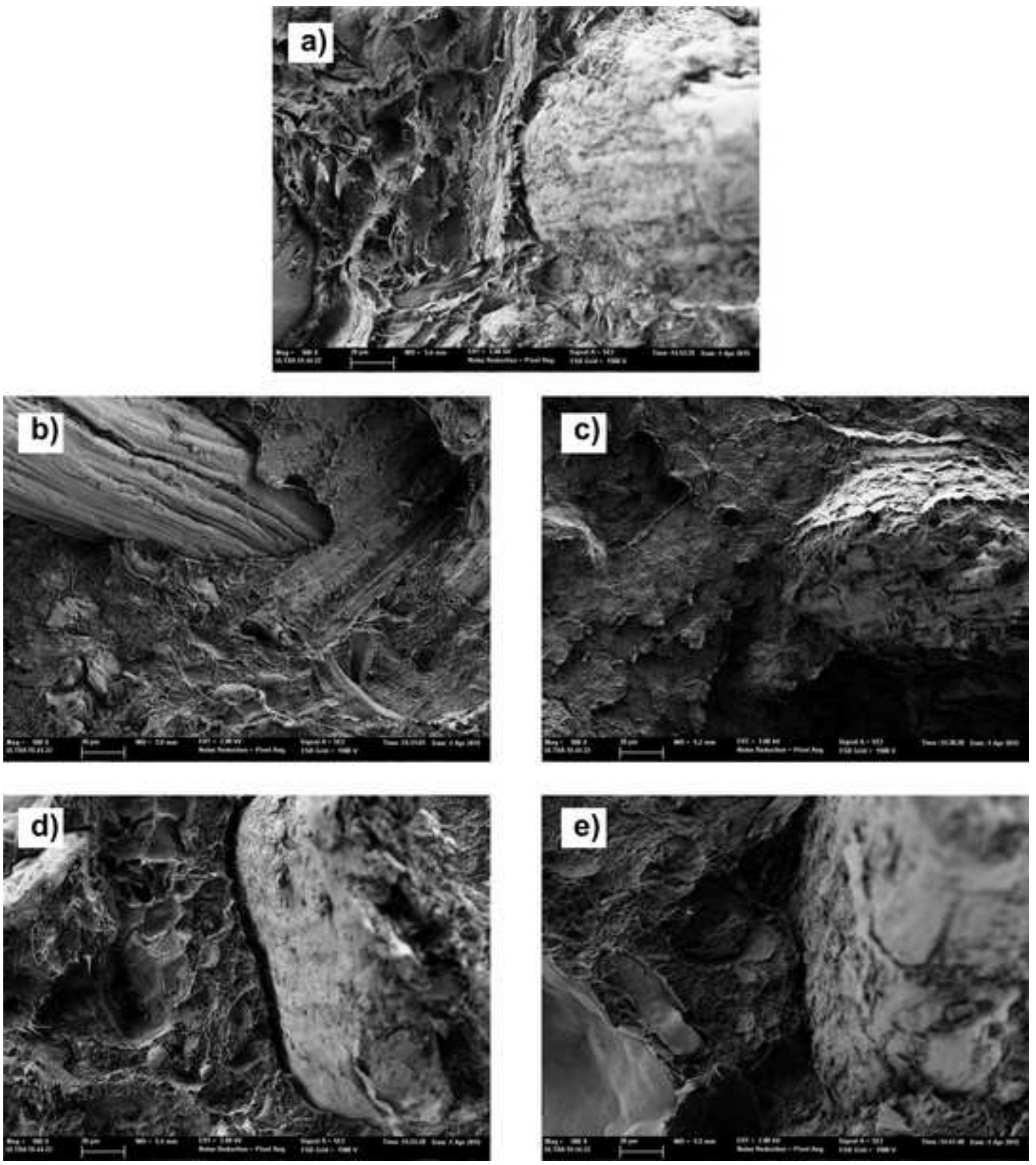


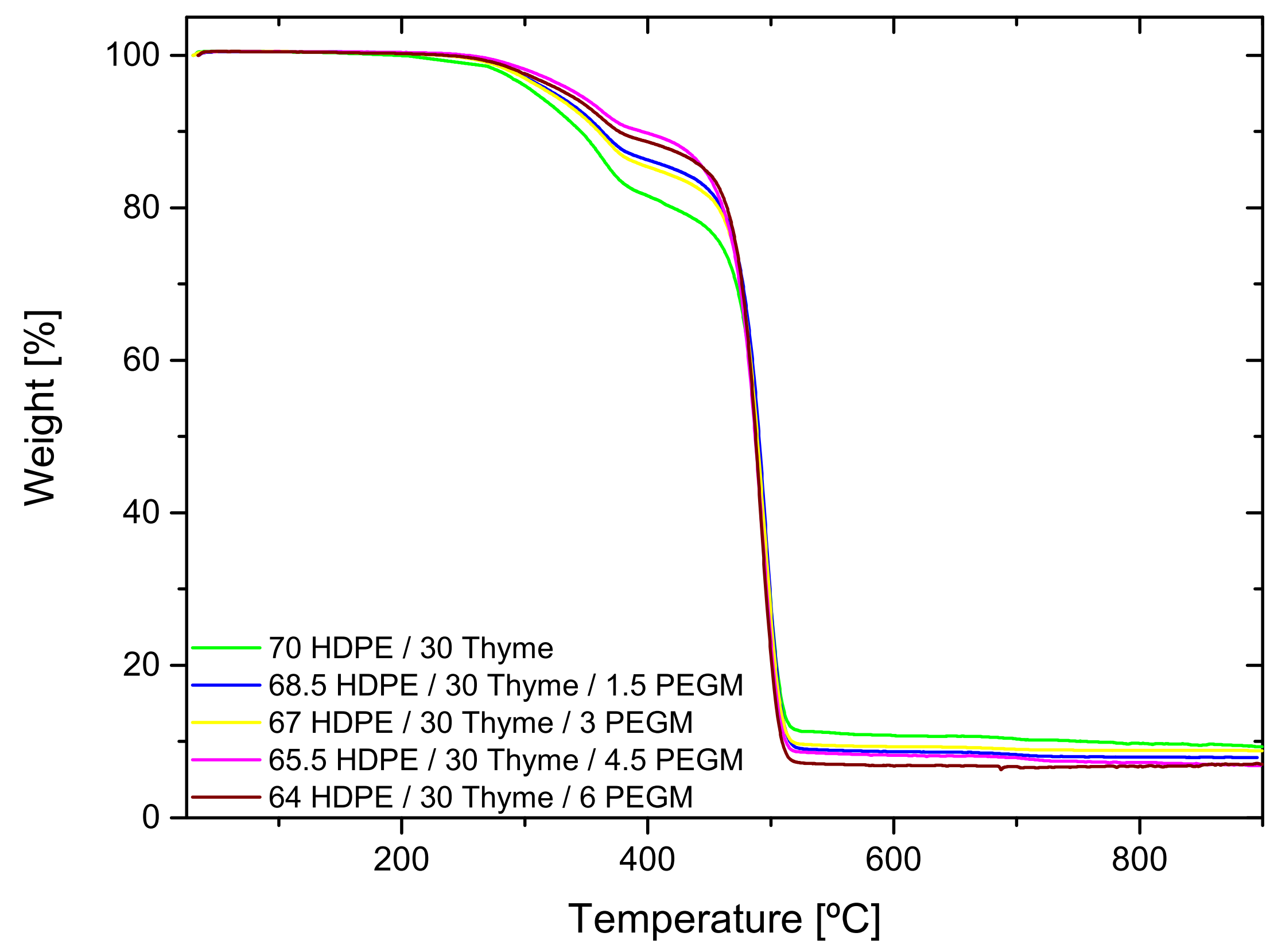




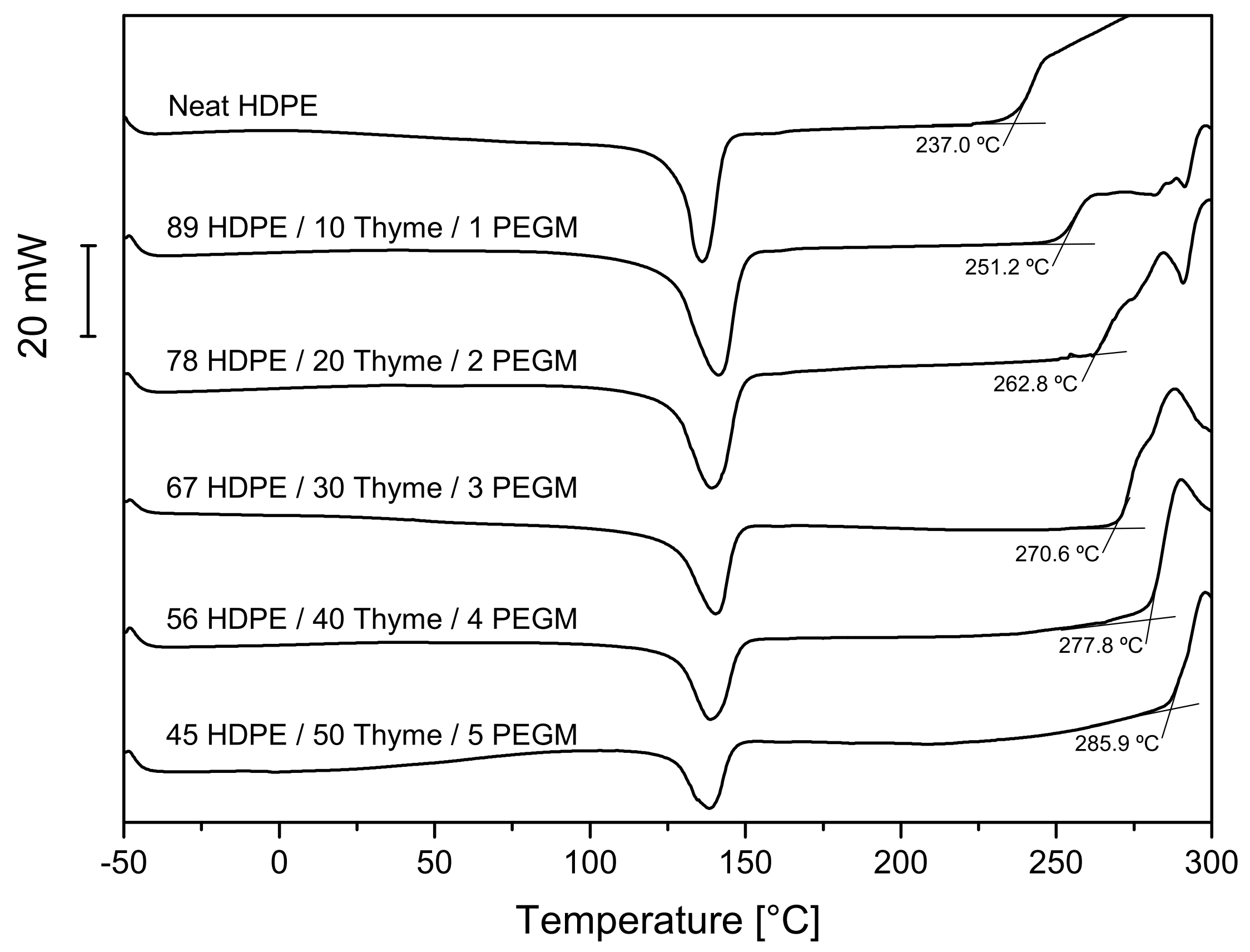




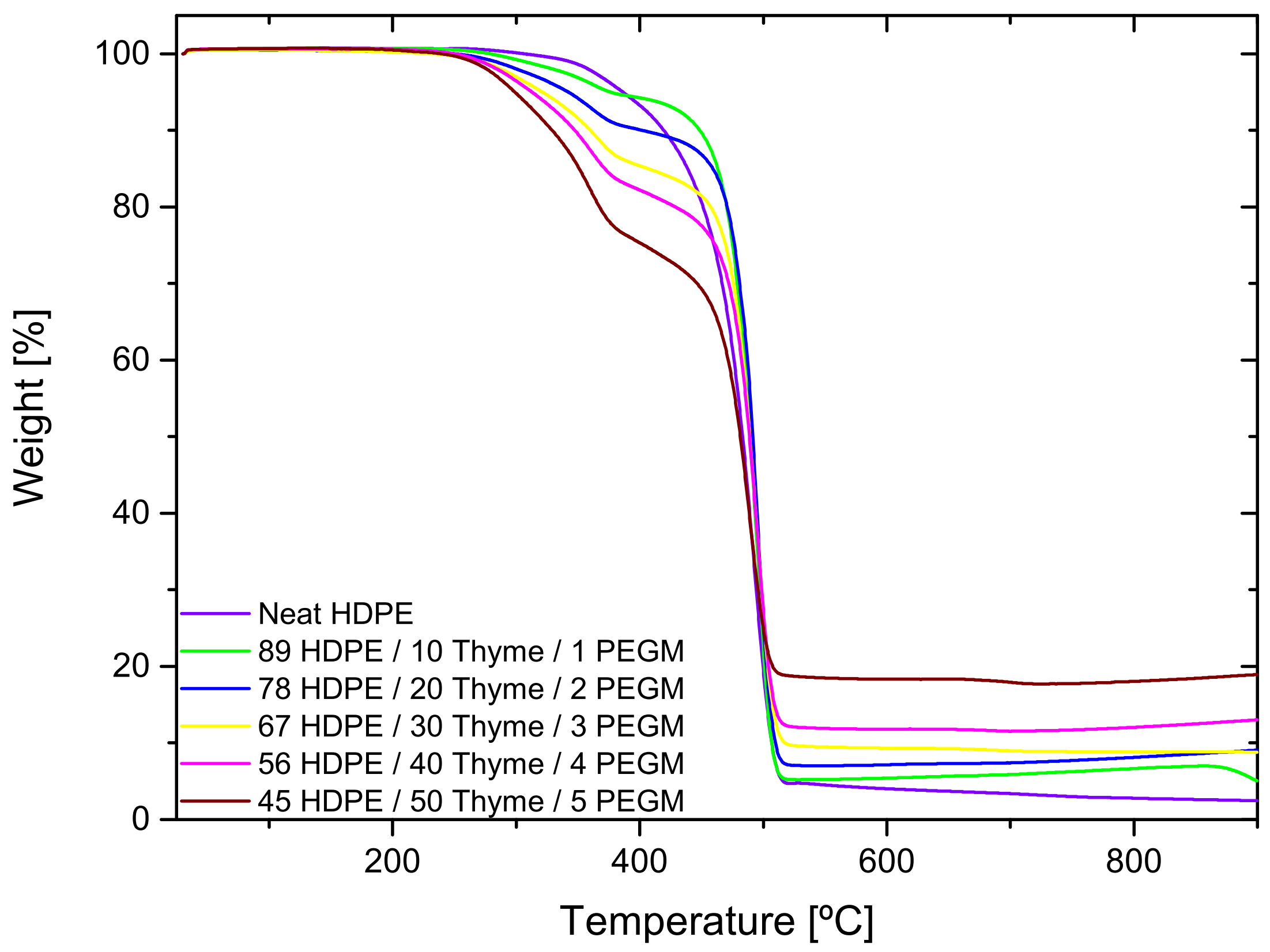




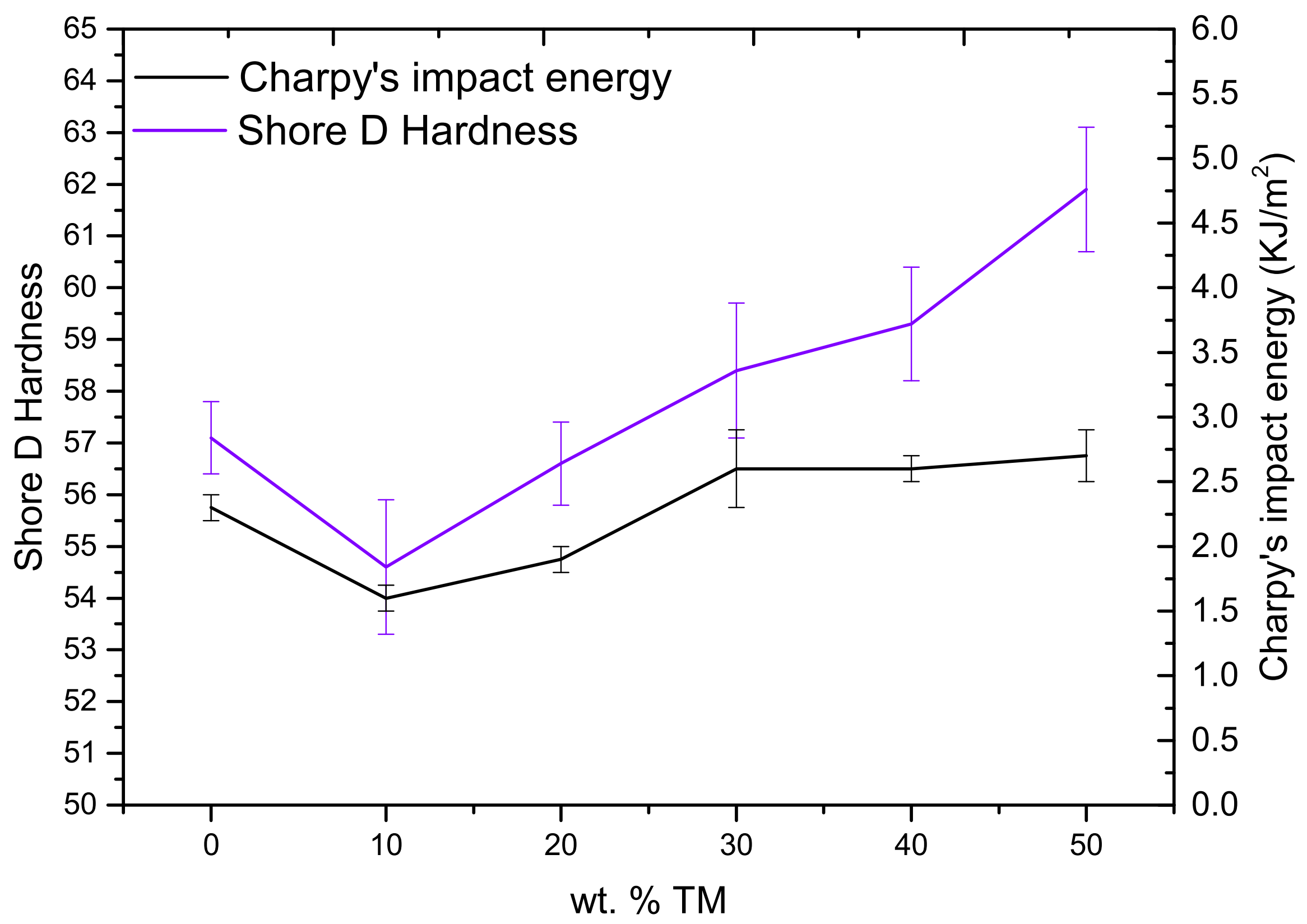


Figure 7.- FESEM images of fractured surfaces from impact test of

HDPE/thyme composites at $500 \times$ with varying thyme filler content
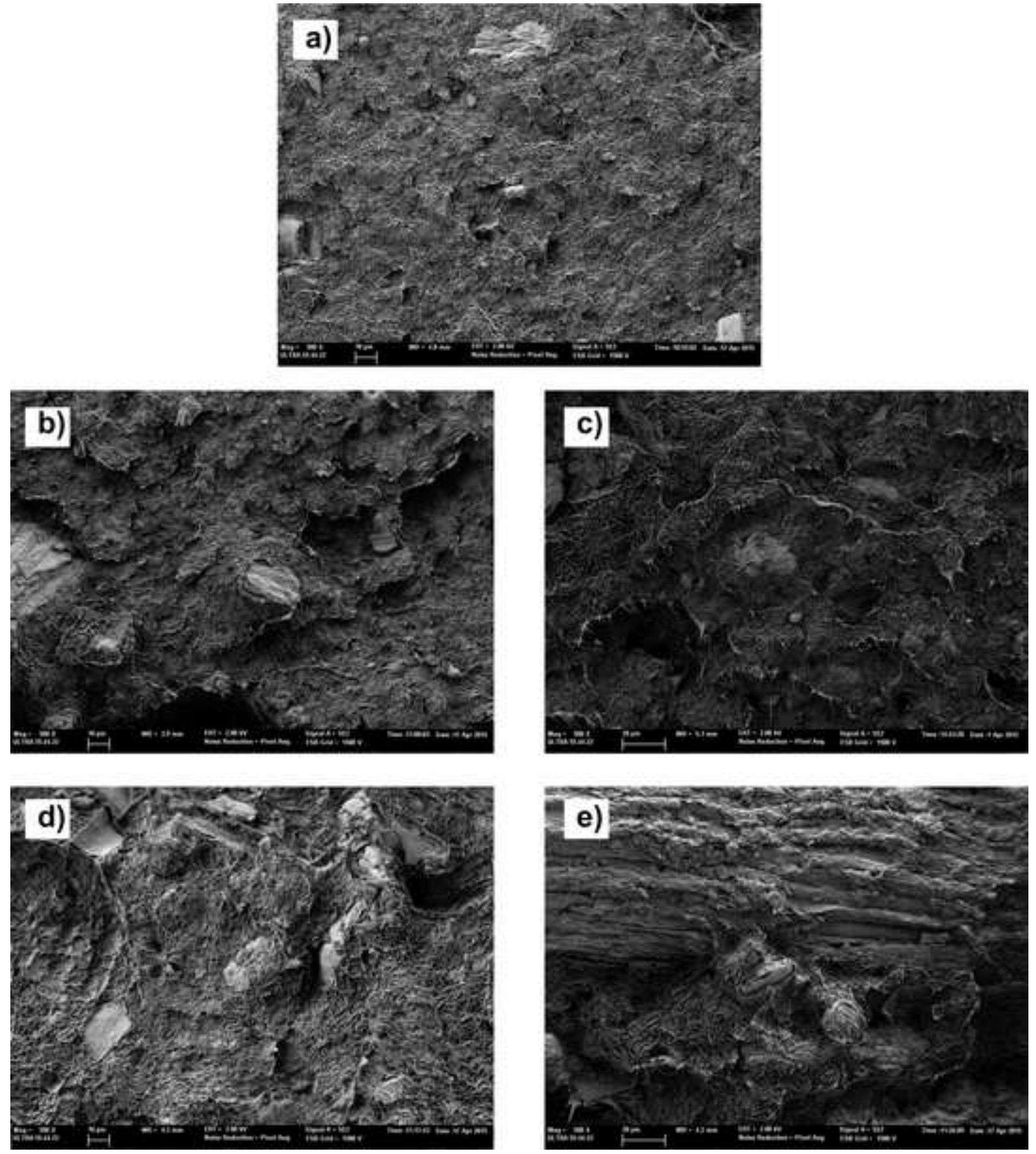


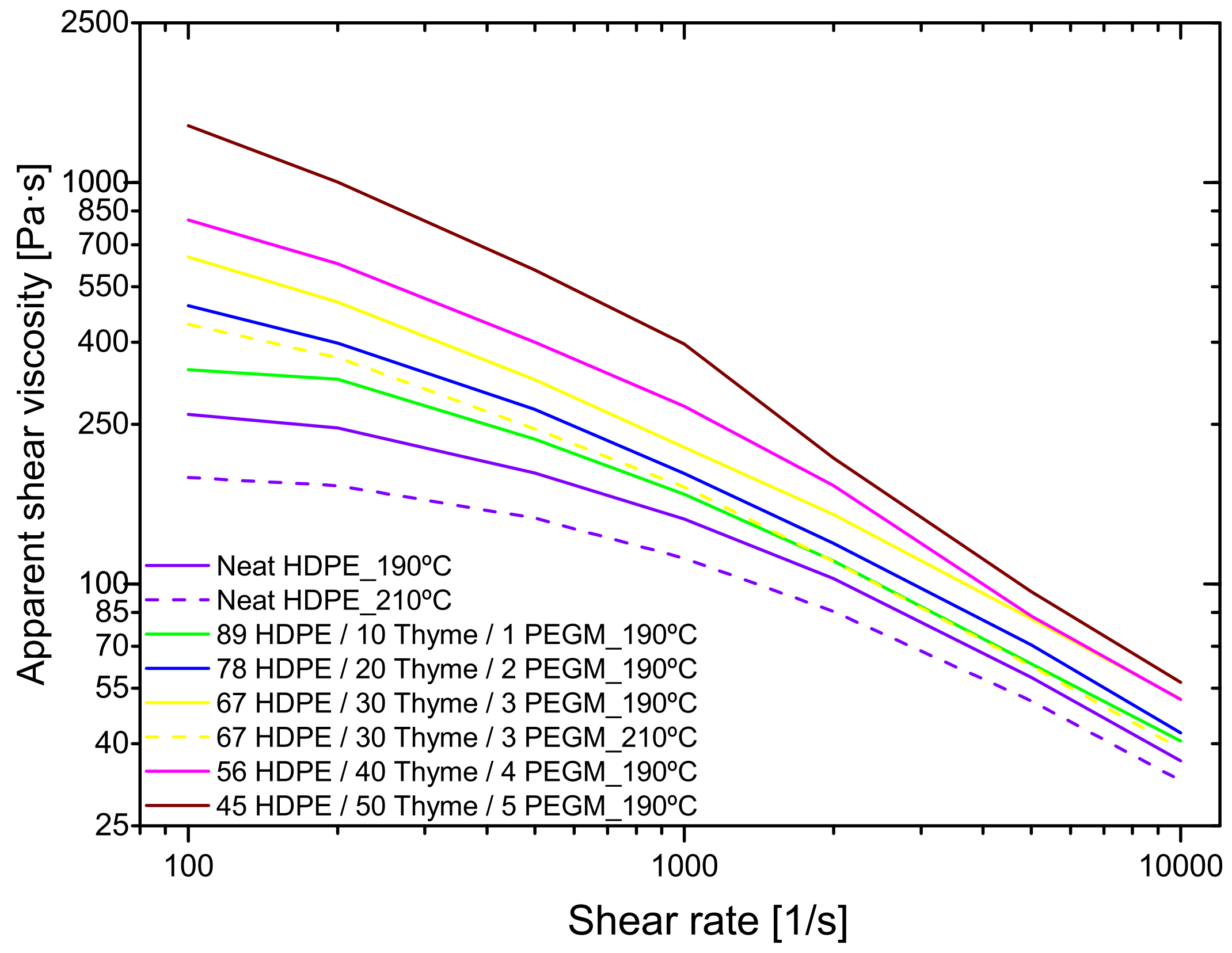


Table 1.- Compositions of HDPE/thyme composites and sample labelling.

Table 1.- Compositions of HDPE/thyme composites and sample labelling.

\begin{tabular}{|c|c|c|c|c|c|c|}
\hline Sample & $\begin{array}{l}\text { HDPE } \\
\text { wt\% }\end{array}$ & $\begin{array}{l}\text { Thyme } \\
\text { wt\% }\end{array}$ & $\begin{array}{l}\text { PEA } \\
\text { wt\% }\end{array}$ & $\begin{array}{c}\text { PVAE } \\
\text { wt\% }\end{array}$ & $\begin{array}{c}\text { PEGM } \\
\text { wt\% }\end{array}$ & $\begin{array}{c}\text { PEMAGM } \\
\text { wt } \%\end{array}$ \\
\hline Neat HDPE & 100 & - & - & - & - & - \\
\hline 70 HDPE / 30 Thyme & 70 & 30 & - & - & - & - \\
\hline 67 HDPE / 30 Thyme / 3.0 PEA & 67 & 30 & 3.0 & - & - & - \\
\hline 67 HDPE / 30 Thyme / 3.0PVAE & 67 & 30 & - & 3.0 & - & - \\
\hline 67 HDPE / 30 Thyme / 3.0PEGM & 67 & 30 & - & - & 3.0 & - \\
\hline 67 HDPE / 30 Thyme / 3.0PEMAGM & 67 & 30 & - & - & - & 3.0 \\
\hline 68.5 HDPE / 30 Thyme / 1.5PEGM & 68.5 & 30 & - & - & 1.5 & - \\
\hline 65.5 HDPE / 30 Thyme / 4.5PEGM & 65.5 & 30 & - & - & 4.5 & - \\
\hline 64 HDPE / 30 Thyme / 6.0PEGM & 64 & 30 & - & - & 6.0 & - \\
\hline 89 HDPE / 10 Thyme / 1.0PEGM & 89 & 10 & - & - & 1.0 & - \\
\hline 78 HDPE / 20 Thyme / 2.0PEGM & 78 & 20 & - & - & 2.0 & - \\
\hline 56 HDPE / 40 Thyme / 4.0PEGM & 56 & 40 & - & - & 4.0 & - \\
\hline 45 HDPE / 50 Thyme / 5.0PEGM & 45 & 50 & - & - & 5.0 & - \\
\hline
\end{tabular}


Table 2.- Summary of the main thermal parameters of HDPE/thyme composites containing a constant filler content of $30 \mathrm{wt} \%$ compatibilized with a constant amount (3 wt\%) of four different ethylene-based copolymers as compatibilizing agents, obtained by differential scanning calorimetry (DSC) and thermogravimetric analysis (TGA).

\begin{tabular}{|c|c|c|c|c|}
\hline & \multicolumn{3}{|c|}{ DSC results } & \multirow{2}{*}{$\begin{array}{c}\text { TGA results } \\
T_{2 w t} \% \text { weight } \\
\text { loss }\left({ }^{\circ} \mathrm{C}\right)\end{array}$} \\
\hline & $\begin{array}{c}\text { Melting } \\
\text { temperature } \\
\left({ }^{\circ} \mathrm{C}\right)\end{array}$ & $\begin{array}{l}\text { Normalized } \\
\text { Enthalpy }(\mathrm{J} / \mathrm{g})\end{array}$ & $\begin{array}{c}\text { Degradation } \\
\text { onset } \\
\text { temperature }\left({ }^{\circ} \mathrm{C}\right)\end{array}$ & \\
\hline Neat HDPE & 134.5 & 178.23 & 237.0 & 364.5 \\
\hline 70 HDPE / 30 Thyme & 137.3 & 142.48 & 270.8 & 278.0 \\
\hline 67 HDPE / 30 Thyme / 3.0 PEA & 142.9 & 111.69 & 268.6 & 294.7 \\
\hline $\begin{array}{l}\text { 67 HDPE / } 30 \text { Thyme / } \\
\text { 3.0PVAE }\end{array}$ & 137.6 & 130.05 & 273.8 & 275.3 \\
\hline $\begin{array}{l}\text { 67 HDPE / } 30 \text { Thyme / } \\
\text { 3.0PEGM }\end{array}$ & 140.4 & 133.72 & 270.6 & 287.3 \\
\hline $\begin{array}{l}\text { 67 HDPE / } 30 \text { Thyme / } \\
\text { 3.0PEMAGM }\end{array}$ & 136.7 & 142.66 & 272.3 & 286.0 \\
\hline
\end{tabular}


Table 3.- Mechanical properties for neat HDPE and HDPE/thyme composites with constant thyme content (30 wt\%) with four different compatibilizer agents (3 wt $\%$ of thyme filler) derived from ethylenebased copolymers.

\begin{tabular}{|c|c|c|c|c|c|c|c|}
\hline Composition & $\begin{array}{c}\text { Tensile } \\
\text { Modulus } \\
\text { (MPa) }\end{array}$ & $\begin{array}{c}\text { Tensile } \\
\text { Strength } \\
\text { (MPa) }\end{array}$ & $\begin{array}{c}\text { Elongation } \\
(\%)\end{array}$ & $\begin{array}{c}\text { Flexural } \\
\text { Modulus } \\
\text { (MPa) }\end{array}$ & $\begin{array}{c}\text { Flexural } \\
\text { Strength } \\
\text { (MPa) }\end{array}$ & $\begin{array}{l}\text { Shore D } \\
\text { Hardness }\end{array}$ & $\begin{array}{c}\text { Charpy's } \\
\text { impact energy } \\
\left(\mathrm{kJ} \mathrm{m}^{-2}\right)\end{array}$ \\
\hline Neat HDPE & $373 \pm 8.61$ & $19.6 \pm 0.2$ & $520 \pm 8.8$ & $804.7 \pm 30.0$ & $23.9 \pm 0.2$ & $53.1 \pm 1.4$ & $3.1 \pm 0.2$ \\
\hline 70 HDPE / 30 Thyme & $645 \pm 76.9$ & $16.2 \pm 0.6$ & $2.83 \pm 0.5$ & $1690 \pm 131$ & $27.2 \pm 2.8$ & $57.1 \pm 0.7$ & $2.3 \pm 0.1$ \\
\hline 67 HDPE / 30 Thyme / 3.0 PEA & $600 \pm 74.1$ & $17.6 \pm 0.7$ & $3.18 \pm 0.2$ & $1368 \pm 89.1$ & $26.8 \pm 1.6$ & $56.1 \pm 0.6$ & $2.0 \pm 0.1$ \\
\hline 67 HDPE / 30 Thyme / 3.0PVAE & $644 \pm 40.3$ & $18.2 \pm 0.8$ & $2.72 \pm 0.3$ & $1500 \pm 280$ & $28.8 \pm 3.0$ & $57.7 \pm 1.6$ & $2.1 \pm 0.1$ \\
\hline 67 HDPE / 30 Thyme / 3.0PEGM & $554 \pm 42.1$ & $23.6 \pm 0.7$ & $3.63 \pm 0.4$ & $1369 \pm 99.7$ & $33.2 \pm 2.6$ & $58.4 \pm 1.3$ & $2.6 \pm 0.3$ \\
\hline 67 HDPE / 30 Thyme / 3.0PEMAGM & $491 \pm 31.6$ & $19.2 \pm 0.4$ & $3.97 \pm 0.4$ & $1330 \pm 84.1$ & $27.8 \pm 1.3$ & $57.5 \pm 1.1$ & $2.5 \pm 0.1$ \\
\hline
\end{tabular}


Table 4.- Summary of the main thermal parameters of HDPE/thyme composites containing a constant filler content of $30 \mathrm{wt} \%$ compatibilized with different amounts of poly(ethylene-co-glycidyl methacrylate-PEGM, obtained by differential scanning calorimetry (DSC) and thermogravimetric analysis (TGA).

\begin{tabular}{|c|c|c|c|c|c|}
\hline \multirow[b]{2}{*}{ wt $\%$ PEGM } & \multicolumn{2}{|c|}{ DSC results } & \multicolumn{3}{|c|}{ TGA results } \\
\hline & $\begin{array}{c}\text { Melt peak } \\
\text { temperature }\left({ }^{\circ} \mathrm{C}\right)\end{array}$ & $\begin{array}{c}\text { Onset } \\
\text { degradation } \\
\text { temperature }\left({ }^{\circ} \mathrm{C}\right)\end{array}$ & $\begin{array}{c}\text { Onset } \\
\text { temperature } \\
\text { first step }\left({ }^{\circ} \mathrm{C}\right)\end{array}$ & $\begin{array}{c}\text { Onset } \\
\text { temperature } \\
\text { second step }\left({ }^{\circ} \mathrm{C}\right)\end{array}$ & $\begin{array}{c}\mathbf{T}_{2 \mathrm{wt} \%} \text { weight } \\
\text { loss }\left({ }^{\circ} \mathrm{C}\right)\end{array}$ \\
\hline 0 & 137.3 & 270.8 & 195.0 & 399.3 & 278.0 \\
\hline 1.5 & 140.5 & 270.5 & 236.7 & 422.3 & 288.7 \\
\hline 3.0 & 140.4 & 270.6 & 231.3 & 415.7 & 287.3 \\
\hline 4.5 & 137.3 & 267.8 & 252.7 & 437.0 & 302.7 \\
\hline 6.0 & 139.9 & 264.9 & 234.7 & 428.7 & 293.3 \\
\hline
\end{tabular}


Table 5.- Mechanical properties for neat HDPE and HDPE/thyme composites with constant thyme content (30 wt\%) with different amounts of poly(ethylene-co-glycidyl methacrylate-PEGM.

\begin{tabular}{|l|c|c|c|c|c|c|c|}
\hline $\mathbf{W t} \%$ PEGM & $\begin{array}{c}\text { Tensile } \\
\text { modulus }\end{array}$ & $\begin{array}{c}\text { Tensile } \\
\text { strength } \\
\mathbf{( M P a )}\end{array}$ & $\begin{array}{c}\text { Elongation } \\
\mathbf{( M P a )}\end{array}$ & $\begin{array}{c}\text { Flexural } \\
\text { modulus } \\
\mathbf{( M P a )}\end{array}$ & $\begin{array}{c}\text { Flexural } \\
\text { strength } \\
\mathbf{( M P a})\end{array}$ & $\begin{array}{c}\text { Shore D } \\
\text { hardness }\end{array}$ & $\begin{array}{c}\text { Charpy's impact } \\
\left.\text { energy } \mathbf{( k J} \mathbf{m}^{-2}\right)\end{array}$ \\
\hline $\mathbf{0}$ & $645 \pm 76.9$ & $16.2 \pm 0.6$ & $2.83 \pm 0.5$ & $1690 \pm 131$ & $27.2 \pm 2.8$ & $57.1 \pm 0.7$ & $2.3 \pm 0.1$ \\
\hline $\mathbf{1 . 5}$ & $633 \pm 29.6$ & $21.9 \pm 0.4$ & $4.14 \pm 0.4$ & $1201 \pm 170$ & $32.9 \pm 3.4$ & $57.9 \pm 0.7$ & $1.9 \pm 0.1$ \\
\hline $\mathbf{3 . 0}$ & $554 \pm 42.0$ & $23.6 \pm 0.7$ & $3.63 \pm 0.4$ & $1369 \pm 99.7$ & $33.2 \pm 2.6$ & $58.4 \pm 1.3$ & $2.6 \pm 0.3$ \\
\hline $\mathbf{4 . 5}$ & $596 \pm 50.1$ & $21.5 \pm 0.6$ & $4.07 \pm 0.3$ & $1173 \pm 101$ & $33.3 \pm 1.3$ & $59.0 \pm 1.4$ & $2.1 \pm 0.4$ \\
\hline $\mathbf{6 . 0}$ & $583 \pm 46.1$ & $22.0 \pm 0.4$ & $3.94 \pm 0.3$ & $1199 \pm 91.0$ & $33.1 \pm 2.3$ & $58.0 \pm 0.8$ & $2.5 \pm 0.2$ \\
\hline
\end{tabular}


Table 6.- Mechanical properties (tensile and flexural) of HDPE/thyme composites with varying thyme filler content, compatibilized with poly(ethylene-co-glycidyl methacrylate-PEGM ( $10 \%$ with regard to the total filler content).

\begin{tabular}{|c|c|c|c|c|c|}
\hline wt $\%$ thyme & $\begin{array}{l}\text { Tensile modulus } \\
\text { (MPa) }\end{array}$ & $\begin{array}{c}\text { Tensile } \\
\text { strength (MPa) }\end{array}$ & $\begin{array}{c}\text { Elongation } \\
\qquad(\%)\end{array}$ & $\begin{array}{c}\text { Flexural } \\
\text { Modulus } \\
\text { (MPa) }\end{array}$ & $\begin{array}{c}\text { Flexural } \\
\text { Strength (MPa) }\end{array}$ \\
\hline 0 & $373 \pm 8.61$ & $19.6 \pm 0.2$ & $520 \pm 8.8$ & $804.7 \pm 30.0$ & $23.9 \pm 0.2$ \\
\hline 10 & $473 \pm 14.9$ & $21.1 \pm 0.6$ & $8.47 \pm 0.6$ & $790.0 \pm 81.1$ & $23.5 \pm 1.7$ \\
\hline 20 & $491 \pm 40.3$ & $22.1 \pm 0.9$ & $5.39 \pm 0.5$ & $938.9 \pm 70.7$ & $27.8 \pm 1.2$ \\
\hline 30 & $554 \pm 42.1$ & $23.6 \pm 0.7$ & $3.63 \pm 0.4$ & $1369 \pm 99.7$ & $33.2 \pm 2.6$ \\
\hline 40 & $708 \pm 16.3$ & $24.3 \pm 0.7$ & $2.89 \pm 0.2$ & $1536 \pm 120$ & $34.5 \pm 3.4$ \\
\hline 50 & $760 \pm 30.8$ & $26.0 \pm 0.3$ & $2.45 \pm 0.3$ & $1848 \pm 130$ & $37.1 \pm 3.2$ \\
\hline
\end{tabular}

